Article

\title{
Distinguishing Astragalus mongholicus and Its Planting Soil Samples from Different Regions by ICP-AES
}

\author{
Lin Li ${ }^{1}$, Sihao Zheng ${ }^{1}$, Qingzhen Yang ${ }^{2}$, Shilin Chen ${ }^{3}$ and Linfang Huang ${ }^{1, *}$ \\ 1 Institute of Medicinal Plant Development, Chinese Academy of Medical Sciences \& Peking Union Medical \\ College, Beijing 100193, China; 13323258786@163.com (L.L.); zshzha@163.com (S.Z.) \\ 2 Department of Pharmacy, The First Hospital of Fangshan District, Beijing 102400, China; \\ 15281083341@163.com \\ 3 Institute of Chinese Materia Medica, China Academy of Chinese Medical Sciences, Beijing 100700, China; \\ slchen@implad.ac.cn \\ * Correspondence: lfhuang@implad.ac.cn; Tel.: +86-10-5783-3197; Fax: +86-10-6289-9700 \\ Academic Editor: Christopher W. K. Lam \\ Received: 25 February 2016; Accepted: 7 April 2016; Published: 12 April 2016
}

\begin{abstract}
Daodi herb" enjoys a good reputation for its quality and clinical effects. As one of the most popular daodi herbs, Astragalus membranaceus (Fisch.) Bge var. mongholicus (Bge.) Hsiao (A. membranaceus) is popularly used for its anti-oxidant, anti-inflammatory and immune-enhancing properties. In this study, we used inductively coupled plasma atomic emission spectrometry (ICP-AES) technique to investigate the inorganic elements contents in A. mongholicu and its soil samples from daodi area (Shanxi) and non-daodi areas (Inner Mongolia and Gansu). A total of 21 inorganic elements ( $\mathrm{Pb}, \mathrm{Cd}, \mathrm{As}, \mathrm{Hg}, \mathrm{Cu}, \mathrm{P}, \mathrm{K}, \mathrm{Zn}, \mathrm{Mn}, \mathrm{Ca}, \mathrm{Mg}, \mathrm{Fe}, \mathrm{Se}, \mathrm{B}, \mathrm{Al}, \mathrm{Na}, \mathrm{Cr}, \mathrm{Ni}$, Ba, Ti and $\mathrm{Sr}$ ) were simultaneously determined. Principal component analysis (PCA) was performed to differentiate A. mongholicu and soil samples from the three main producing areas. It was found that the inorganic element characteristics as well as the uptake and accumulation behavior of the three kinds of samples were significantly different. The high contents of $\mathrm{Fe}, \mathrm{B}, \mathrm{Al}, \mathrm{Na}, \mathrm{Cr}$ and $\mathrm{Ni}$ could be used as a standard in the elements fingerprint to identify daodi and non-daodi A. Mongholicus. As the main effective compounds were closely related to the pharmacodynamics activities, the inter-relationships between selected elements and components could reflect that the quality of A. Mongholicus from Shanxi were superior to others to a certain degree. This finding highlighted the usefulness of ICP-AES elemental analysis and evidenced that the inorganic element profile can be employed to evaluate the genuineness of $A$. mongholicus.
\end{abstract}

Keywords: Astragalus membranaceus; inorganic elements; daodi herb; soil; ICP-AES

\section{Introduction}

The term "daodi herb" refers to a concept that has been widely recognized in Chinese medicinal history for centuries. It is defined as "medicinal material that is produced, cultivated, harvested and processed in specific geographic regions with designated natural conditions, ecological environment and particular attention". These factors lead to quality and clinical effects surpass those of the same botanical origin produced from other regions, and thus is widely recognized and has long enjoyed a good reputation. "Daodi herb" is also known as authentic and superior medicinal herbal, geo-herb, authentic medicinal, geo-authentic medicinal material and genuine medicinal material [1].

The dried root of Astragalus membranaceus (Fisch.) Bge var. mongholicus (Bge.) Hsiao (A. membranaceus), one of the most popular daodi herbs, has been widely used as a traditional prescription medicine more than 2000 years in China [2]. Due to its anti-oxidant, anti-inflammatory 
and immune-enhancing properties, A. mongholicus has gained popularity and been used extensively as a dietary supplement to improve health and prevent diseases, such as inflammation, heart disease, aging, and cancer [3,4]. A. mongholicus is mainly grown in the northeast, north, and northwest of China as well as in Mongolia and Korea (A. membranaceus). Shanxi is the daodi-producing areas of A. mongholicus, whose products are famous for "high quality, good effect and large amount".

A. mongholicus is recorded in European Pharmacopoeia (EP, 8.0 version), British Pharmacopoeia (BP, 2013 version), Japanese Pharmacopoeia (JP, 16 version) and Chinese Pharmacopoeia (CP, 2015 version). American "Dietary Supplement Health and Education Act" (DSHEA), European Food Safety Authority (EFSA) and Ministry of Health China (MOH) also recorded A. mongholicus as an herbal dietary supplement. As a dietary supplement, A. mongholicus has abundant biologically active ingredients; organic and inorganic compounds including carbohydrates, proteins; elements like Ca, $\mathrm{P}, \mathrm{K}, \mathrm{Fe}$, and $\mathrm{Mg}$; vitamins (A, C, and B-complex); and dietary fibers [3]. With so many inorganic elements, A. Mongholicus can be a source of minerals with important physiological functions in the human organism. Ca is a major component of bone and response for increasing the density of the capillary wall, and reducing its permeability and leakage [5]. Zn is a co-factor in enzymes, some of which are structures of the nervous system [6]. Being part of hemoglobin, Fe is involved in the transportation of oxygen [7]. $\mathrm{K}$ and $\mathrm{Na}$ play an indispensable role in fluid osmotic pressure and acid-base balance [8]. Abundant inorganic elements in herbs are the formation of some active chemical constituents, thus influencing the medical properties [9]. It is well-known that environmental factors such as soil, climate, light, and humidity directly influence the secondary metabolites (many of which are bioactive constituents) of plants. Studies have shown that mineral nutrition can affect the metabolism of many bioactive constituents in herbs, such as flavonoids, saponin and so on [10,11]. It was reported that the flavonoids, polysaccharide and saponin in Ophiopogon japonicus have a direct relationship with $\mathrm{K}, \mathrm{Fe}, \mathrm{Mn}, \mathrm{B}, \mathrm{Ba}$ and $\mathrm{Zn}$ in its planting soil [12]. The optimum concentration of $\mathrm{K}$ significantly increased the yields of rosmarinic acid, ursolic acid, oleanolic acid and flavonoids in Prunella vulgaris L. [13]. In Salidroside, salidroside was negatively correlated with P and K [14]. At present, the inorganic elements have become a vital factor to evaluate the quality of Chinese herbal medicine originating from different regions and also help in tracking and judging its authenticity according to certain inorganic elements characteristic. Therefore, determination of the type and content of inorganic elements in daodi medicinal materials is essential for understanding their efficacy.

Methods for the determination of inorganic elements are flame atomic absorption spectrometry (FAAS) [15], inductively coupled plasma mass spectrometry (ICP-MS) [16], atomic fluorescence spectrometry (AFS) [17], and so on. Nowadays, the use of ICP-AES is becoming more common in analyzing numerous inorganic elements and obtaining fingerprints of the element pattern. In this way, the technique has been successfully applied to fruits [18], pharmaceutical materials [19], eggs [20] and flowers [21]. As for A. Mongholicus, previous papers were mainly focused on the discrimination of different species and limited studies focus on its origin areas, which was not sufficient and comprehensive enough to research the geoherbalism of the famous traditional Chinese medicine. Our previous studies have shown that the contents of chemical compositions in A. mongholicus from Shanxi were greater than those in Inner Mongolia and Gansu, which suggested that the daodi A. mongholicus is better than others [22-24]. Are there differences in inorganic elemental characteristics in A. mongholicus from daodi and non-daodi areas? In this study, 21 inorganic elements $(\mathrm{Pb}, \mathrm{Cd}, \mathrm{As}, \mathrm{Hg}$, $\mathrm{Cu}, \mathrm{P}, \mathrm{K}, \mathrm{Zn}, \mathrm{Mn}, \mathrm{Ca}, \mathrm{Mg}, \mathrm{Fe}, \mathrm{Se}, \mathrm{B}, \mathrm{Al}, \mathrm{Na}, \mathrm{Cr}, \mathrm{Ni}, \mathrm{Ba}, \mathrm{Ti}$ and $\mathrm{Sr}$ ) in A. mongholicus and soil samples were determined by ICP-AES. The differences between daodi and non-daodi A. mongholicus were then investigated, thereby providing a theoretical basis for the relationship between the elements and the medicinal value of Chinese herbal medicine. 


\section{Results and Discussion}

\subsection{Internal Quality Controls of ICP-AES Procedure}

\subsubsection{Detecting Wavelength and Detection Limit}

The determination was investigated for each element by recording the spectra of the sample solution and potentially interfering elements near the analytical line. First, Select the spectral lines for detection that have little spectral interference and high precision. A compromise between the most sensitive spectral line of each analyte and lower background interference was used to select the optimum spectral lines for this study. The capability of the method as a routine analysis method was estimated through the determination of the limits of detection (LOD, $\mathrm{mg} / \mathrm{L}$ ) and limits of quantification (LOQ) of every element studied. The LOD was calculated according to Boumans using $3 \sigma$ and LOQ using $9 \sigma$ for pure element standards by measuring an appropriate reagent blank solution ten times and digested sample solutions three times. The elemental analysis wavelengths and the LOD values are presented in Table 1. The LOD values for the 21 elements were in the range of $0.01-0.48 \mathrm{mg} / \mathrm{L}$. Compared with the determined results of samples, the LOD values were adequate for almost all elements to determine the elements in preserved samples.

Table 1. Work curve, limit of detection and recovery.

\begin{tabular}{|c|c|c|c|c|c|c|}
\hline Element & $\begin{array}{l}\text { Wavelength } \\
\text { (nm) }\end{array}$ & Regression Equation & LOD, mg/L & $\mathrm{LOQ}, \mathrm{mg} / \mathrm{L}$ & $\begin{array}{c}\text { Average } \\
\text { Recovery (\%) }\end{array}$ & RSD (\%) \\
\hline $\mathrm{Pb}$ & 220.54 & $y=171.5763 x+2.0716$ & 0.24 & 0.72 & 109.7 & 3.5 \\
\hline $\mathrm{Cd}$ & 228.50 & $y=2712.5644 x+6.1782$ & 0.04 & 0.12 & 93.7 & 5.5 \\
\hline As & 193.69 & $y=159.8310 x-1.5560$ & 0.01 & 0.03 & 108.7 & 6.5 \\
\hline $\mathrm{Cu}$ & 324.75 & $y=4410.2400 x-4.4859$ & 0.07 & 0.21 & 95.3 & 5.8 \\
\hline $\mathrm{P}$ & 213.62 & $y=16.8398 x-0.0549$ & 0.11 & 0.33 & 96.7 & 1.6 \\
\hline K & 766.49 & $y=3246.1758 x-114.7232$ & 0.08 & 0.24 & 113.3 & 3.3 \\
\hline $\mathrm{Zn}$ & 213.85 & $y=2226.9064+6.2482$ & 0.08 & 0.24 & 104.3 & 2.9 \\
\hline Mn & 257.61 & $y=14,069.62 x+4.9874$ & 0.03 & 0.06 & 91.7 & 5.6 \\
\hline $\mathrm{Ca}$ & 317.93 & $y=5090.8325 x+15.5628$ & 0.14 & 0.42 & 89.0 & 4.5 \\
\hline $\mathrm{Mg}$ & 279.50 & $y=100,774.53 x+14.3562$ & 0.17 & 0.51 & 88.3 & 3.5 \\
\hline $\mathrm{Fe}$ & 259.93 & $y=2422.3150 x-0.5618$ & 0.06 & 0.18 & 100.3 & 8.1 \\
\hline Se & 196.02 & $y=92.5530 x+0.9983$ & 0.20 & 0.60 & 100.7 & 3.0 \\
\hline B & 249.67 & $y=3074.1732 x+12.5746$ & 0.02 & 0.06 & 93.3 & 3.3 \\
\hline $\mathrm{Al}$ & 308.21 & $y=1544.3306 x-17.5037$ & 0.04 & 0.12 & 106.7 & 0.5 \\
\hline $\mathrm{Na}$ & 589.59 & $y=1605.8634 x-313.4292$ & 0.09 & 0.27 & 93.3 & 1.6 \\
\hline $\mathrm{Cr}$ & 267.71 & $y=5825.6772 x+8.5930$ & 0.08 & 0.24 & 85.0 & 4.7 \\
\hline $\mathrm{Ni}$ & 231.60 & $y=1401.1639 x-0.0311$ & 0.06 & 0.18 & 113.7 & 4.2 \\
\hline $\mathrm{Ba}$ & 455.40 & $y=61,217.94 x+202.9208$ & 0.48 & 1.44 & 111.0 & 2.4 \\
\hline $\mathrm{Hg}$ & 194.16 & $y=475.7408 x+2.5548$ & 0.06 & 0.18 & 98.0 & 6.4 \\
\hline $\mathrm{Ti}$ & 334.94 & $y=1892.2594 x+15.4562$ & 0.09 & 0.27 & 94.0 & 3.8 \\
\hline $\mathrm{Sr}$ & 407.77 & $y=3059.3525 x+5.526$ & 0.11 & 0.33 & 114.0 & 4.0 \\
\hline
\end{tabular}

\subsubsection{Calibration Studies}

To determine the linearity of the response vs. concentration for the elements, a series of standard solutions for ICP-AES were analyzed. The calibration curves and regression analysis on calibration curves are presented in Table 1. A good linear relationship between the corresponding sensitivities and the concentrations of the elements was achieved. All linear correlation coefficients were greater than 0.9990 .

\subsubsection{Accuracy and Precision of the Method}

To ensure the accuracy of the experiment, spiking experiments of each sample were conducted. Each standard solution whose concentration was close to sample was added into the sample. Samples with added after standard digestions were determined using ICP-AES. Results from the recovery experiments for all elements in herb samples after digestion are listed in Table 1. For acceptance of data, the average recovery rates had to fall within a range of $85.0 \%-114.0 \%$, which demonstrated that the method has acceptable accuracy and is suitable for simultaneous determination of 21 inorganic 
elements in A. mongholicus and its soil samples. The precision expressed as relative standard deviation (RSD) ranged from $0.5 \%$ to $8.1 \%$.

\subsection{Inorganic Elements in the Soil}

From the 21 studied elements, 18 elements $(\mathrm{Pb}, \mathrm{Cd}, \mathrm{As}, \mathrm{Cu}, \mathrm{P}, \mathrm{K}, \mathrm{Zn}, \mathrm{Mn}, \mathrm{Ca}, \mathrm{Mg}, \mathrm{Fe}, \mathrm{Se}, \mathrm{B}, \mathrm{Al}$, $\mathrm{Na}, \mathrm{Cr}, \mathrm{Ni}$ and $\mathrm{Ba}$ ) were found in soil samples obtained from Shanxi, Inner Mongolia and Gansu. For the rest of elements, the contents found in all samples were lower than the limit of detection (LOD) values. The results are shown in Figure 1. By comparing the total contents of the 18 elements in the soil samples, we found that the contents of some elements varied largely. For example, the average content of Se in soil samples from Shanxi was $14,890 \mathrm{mg} / \mathrm{kg}$ while that from Inner Mongolia was $4539 \mathrm{mg} / \mathrm{kg}$. The highest amounts of $\mathrm{P}$ found in samples of Shanxi was $1338 \mathrm{mg} / \mathrm{kg}$, whereas the lowest level from Inner Mongolia was $386 \mathrm{mg} / \mathrm{kg}$. In the case of Ca, the mean concentration of samples from Gansu was almost four-fold higher than that from Inner Mongolia. However, the difference for some elements was not so marked. For example, the mean concentration of $\mathrm{K}$ was $321 \mathrm{mg} / \mathrm{kg}$ in the soil samples from Inner Mongolia and $324 \mathrm{mg} / \mathrm{kg}$ in that from Gansu. Furthermore, the inorganic elements in all soil samples were seen to decrease in the following order: $\mathrm{Se}>\mathrm{Ca}>\mathrm{Al}>\mathrm{Fe}>\mathrm{Mg}>\mathrm{P}>\mathrm{K}>\mathrm{Mn}>\mathrm{Na}>\mathrm{Ba}$ $>\mathrm{Zn}>\mathrm{Cr}>\mathrm{B}>\mathrm{Cu}>\mathrm{Ni}>\mathrm{Pb}>\mathrm{As}>\mathrm{Cd}$.

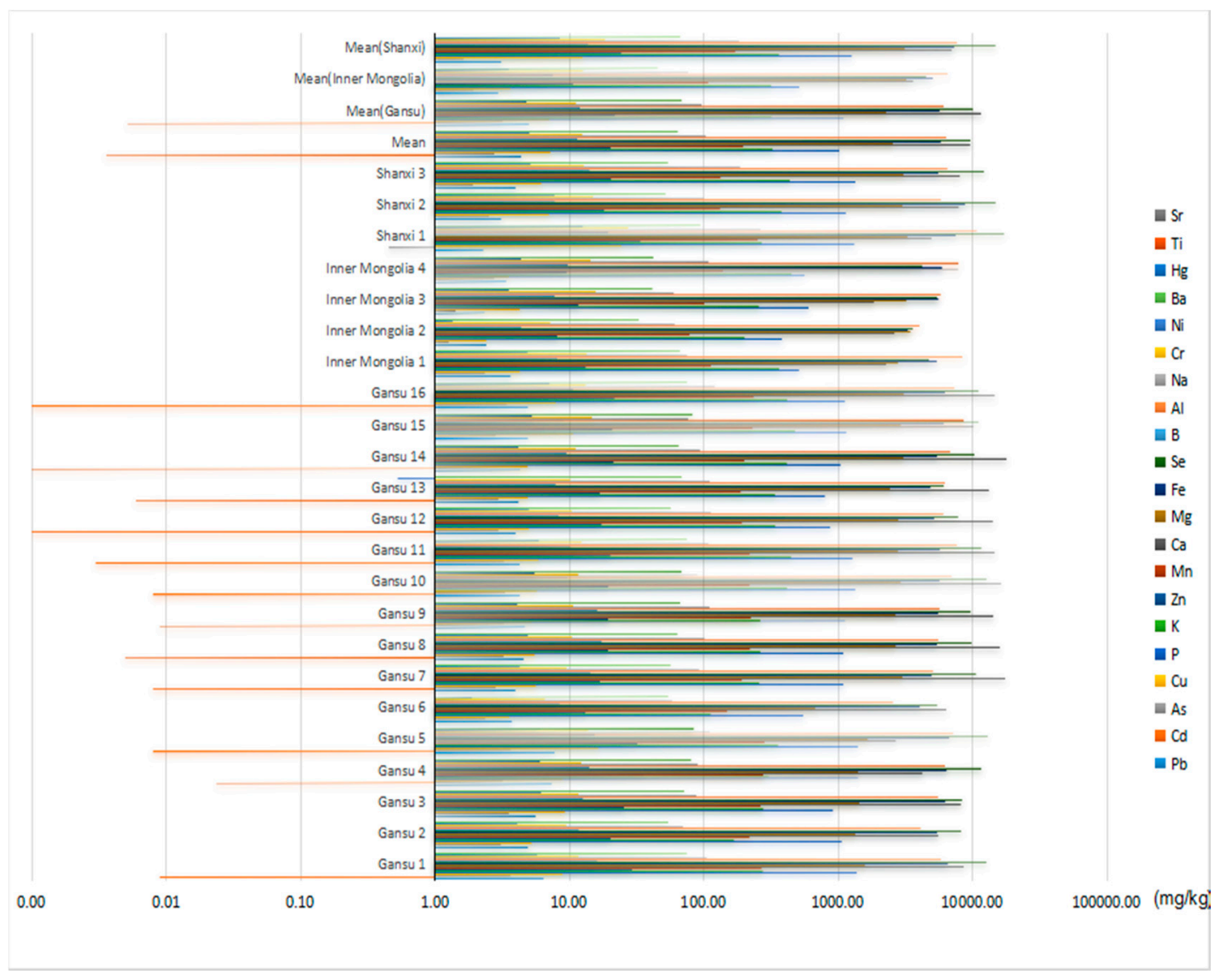

Figure 1. Elemental concentrations in soil samples.

According to the theory of biogeochemistry, the accumulation of inorganic elements in plants has direct relationships with the geochemical distribution and migration of the element, the chemical composition of geological and metallogenic backgrounds and parent material of the soil, namely, plants cultivated in different geological environments probably vary in the accumulation of inorganic elements, thus vary in pharmacological effects. Only herb cultivated in those special soils may meet the standard of daodi traditional Chinese medicine. 


\subsection{PCA for Inorganic Elements in Soil of A. mongholicus}

Principal component analysis (PCA) is a method to describe the relationships of multidimensional data arrays between variables and objects by greatly reducing data and presenting different manners for interpretation. Thus far, PCA has emerged as a promising tool for the classification of food samples in terms of its type, level, provenance, and quality. There were three groups in the scores plot (Figure 2), composed of soil samples from Shanxi, Inner Mongolia and Gansu, respectively, indicating differences in their mineral composition in soil. Soil samples from different producing areas could by completely separated from each other without overlap, which showed that inorganic elements could distinguish soil samples from different producing areas effectively.

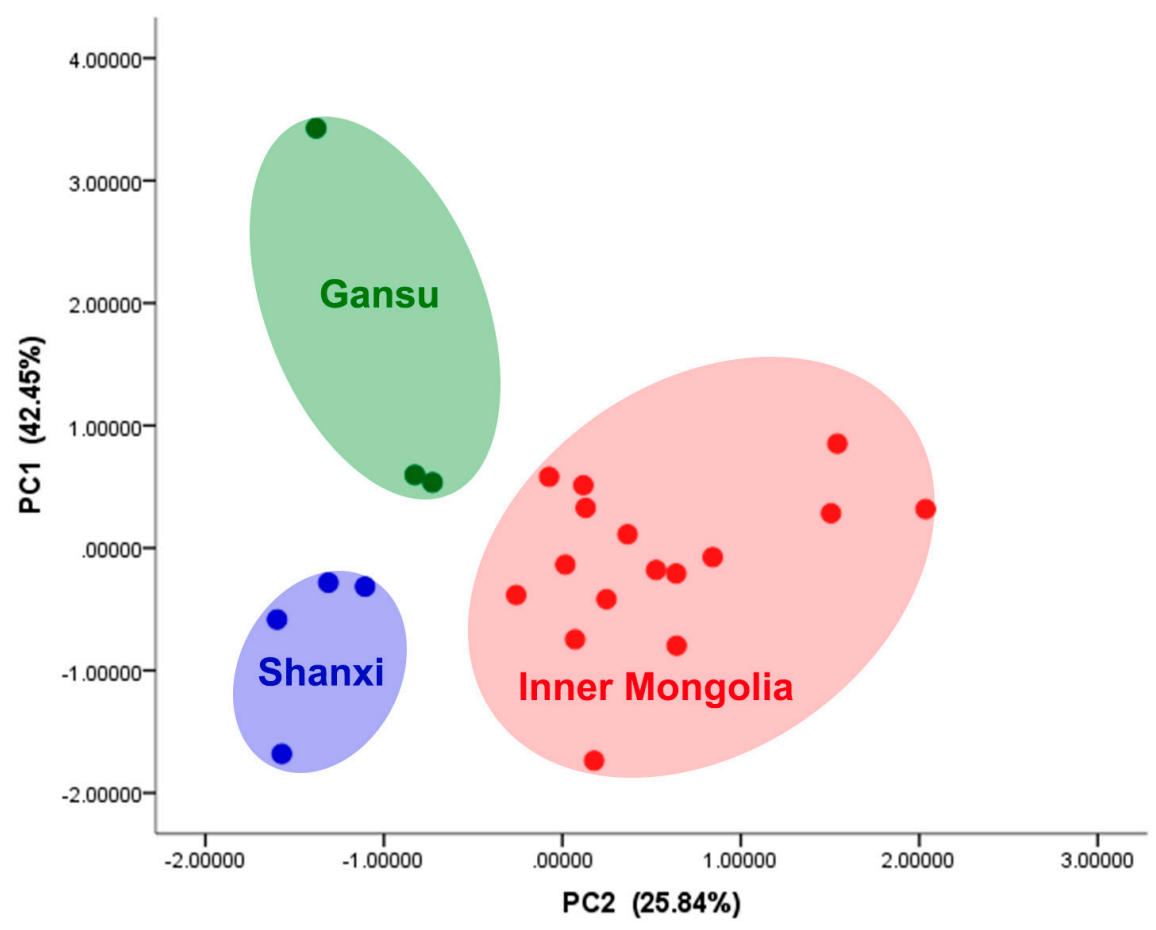

Figure 2. PCA for inorganic elements in soil.

\subsection{Contents of Inorganic Elements in A. mongholicus}

All of the elemental concentrations obtained in A. mongholicus samples from the three sampling sites are summarized in Figure 3. As shown, the contents of the 18 elements ranged from 0 to $7292 \mathrm{mg} / \mathrm{kg}$; thus, the differences of the contents between various elements were significant. The P was, quantitatively, the most abundant mineral, having a mean concentration of $4859 \mathrm{mg} / \mathrm{kg}$. Other elements, such as $\mathrm{Ca}, \mathrm{K}, \mathrm{Mg}$ and $\mathrm{Fe}$, were also presented in large amounts in the samples with mean concentrations of $1068 \mathrm{mg} / \mathrm{kg}, 949 \mathrm{mg} / \mathrm{kg}, 546 \mathrm{mg} / \mathrm{kg}$ and $328 \mathrm{mg} / \mathrm{kg}$, respectively. In all analyzed plant samples, the contents of Se and Cd did not exceed $0.1 \mathrm{mg} / \mathrm{kg}$. According to the different geographic regions analyzed, it can be concluded that Shanxi samples contained almost $2 \sim 4$ fold the levels of $\mathrm{Fe}, \mathrm{B}, \mathrm{Al}, \mathrm{Na}, \mathrm{Cr}, \mathrm{Ni}$ and $\mathrm{Ba}$ than samples from Inner Mongolia and Gansu. Among them, $\mathrm{Fe}$, $\mathrm{Cr}$ and $\mathrm{Ni}$ are necessary trace elements for human body according to the World Health Organization (WHO) [25]. In contrast, the Shanxi samples were poorer in $\mathrm{P}, \mathrm{K}$ and Se than other samples, especially Se was 6 7 fold levels lower. Moreover, Gansu included much higher content of $\mathrm{Zn}$ in comparison with other origins. For the rest of the elements, the three regions had no significant variability. 


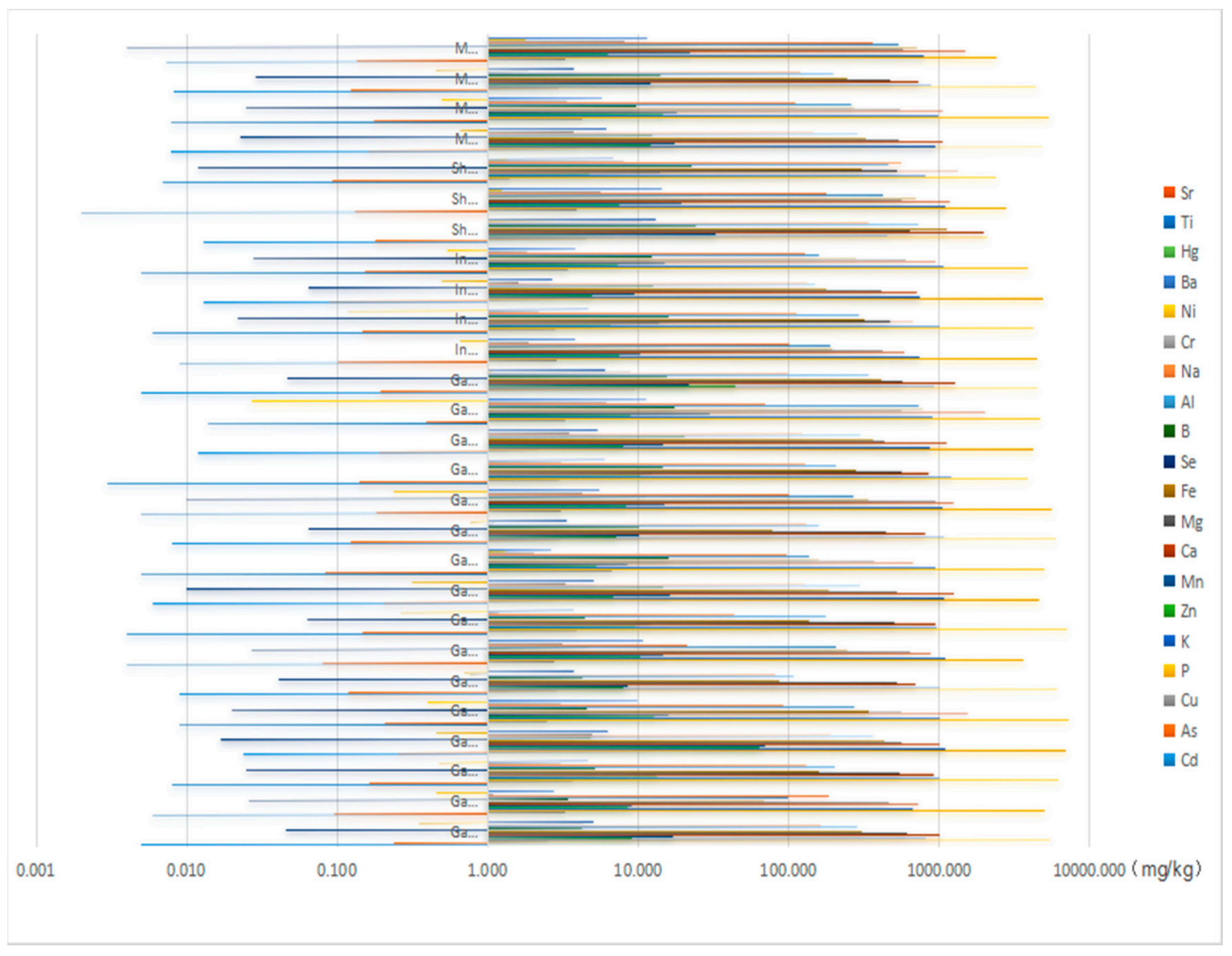

Figure 3. Elemental concentrations in herb samples.

Every daodi herb may have its own characteristic elements fingerprint. Our results showed that the difference in contents of inorganic elements among the three origins was significant. The high contents of $\mathrm{Fe}, \mathrm{B}, \mathrm{Al}, \mathrm{Na}, \mathrm{Cr}$ and $\mathrm{Ni}$ may be used as a standard in the elements fingerprint to identify daodi and non-daodi A. mongholicus [26].

\subsection{PCA for Inorganic Elements in A. mongholicus}

According to the scores plot (Figure 4), the formation of two main groups was observed. One group was formed exclusively by the herb samples from Shanxi, and the other group was perceptibly formed by two subgroups, namely Gansu and Inner Mongolia. This separation was attributed to the closeness of the sampling points. The result showed that the A. mongholicus from Gansu was significantly different from the other origins and the Shanxi and Inner Mongolia samples had some similarities in mineral composition by gathering in the left part. The application of PCA confirmed the differences between daodi and non-daodi A. mongholicus.

\subsection{Uptake and Accumulation Behavior}

Given that each plant has its own inorganic elements uptake and accumulation behavior, the content in plant depending on content in soil was not considered justifiable [27]. The correlation data in terms of linear correlation coefficient values between inorganic elements and chemical compositions that were significant at 95\% and 99\% confidence level was examined. The results are shown in Figure 5. $\mathrm{Ca}$ and Fe showed high and significant correlations at $99 \%$ confidence level with $\mathrm{Al}, \mathrm{Cr}$ and $\mathrm{Ba}$. Mn also showed this tendency with $\mathrm{Pb}, \mathrm{Cd}$ and $\mathrm{Cu}$, whereas $\mathrm{K}$ and $\mathrm{P}$ had high negative correlations with most of the inorganic elements. The results indicated that the uptake of these elements in A. mongholicus might have a synergistic or inhibiting effect. 


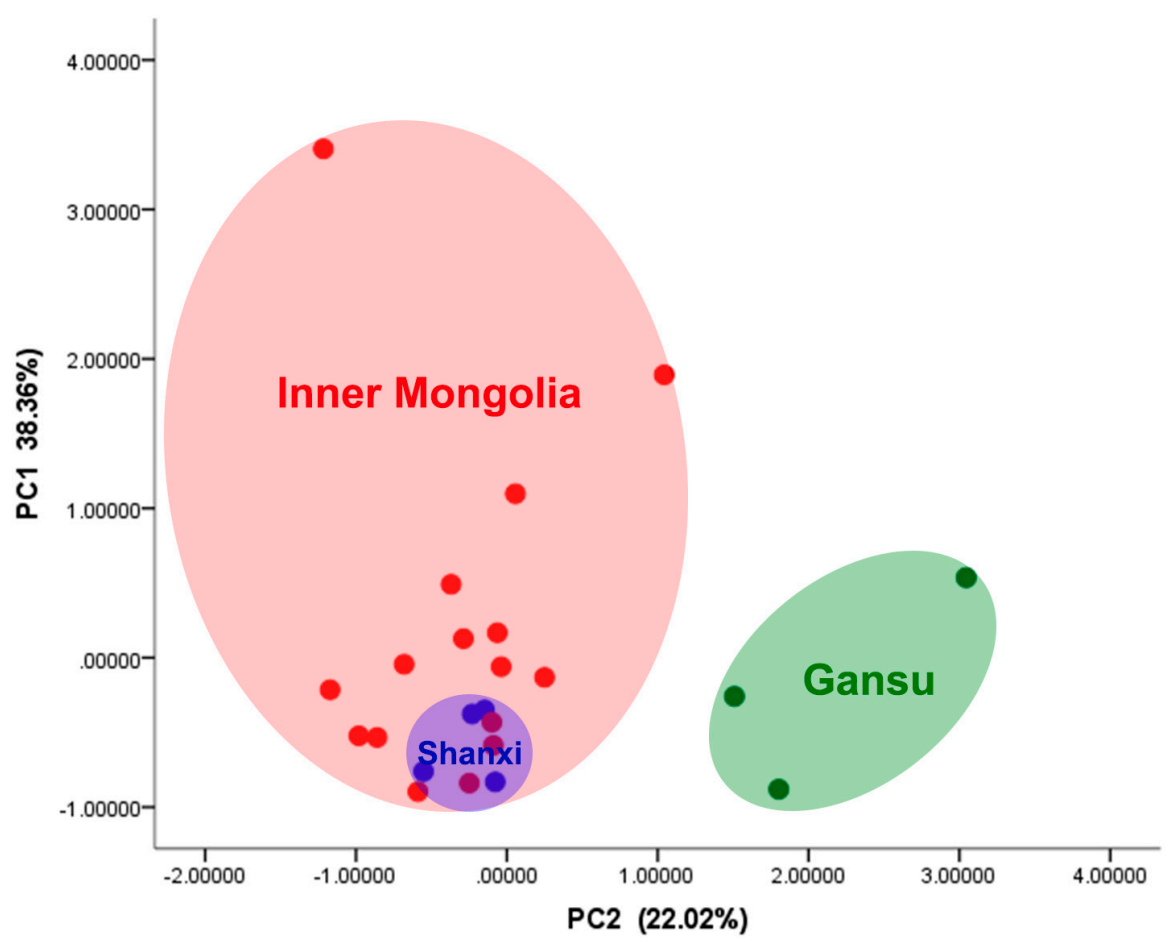

Figure 4. PCA for inorganic elements in herbs.

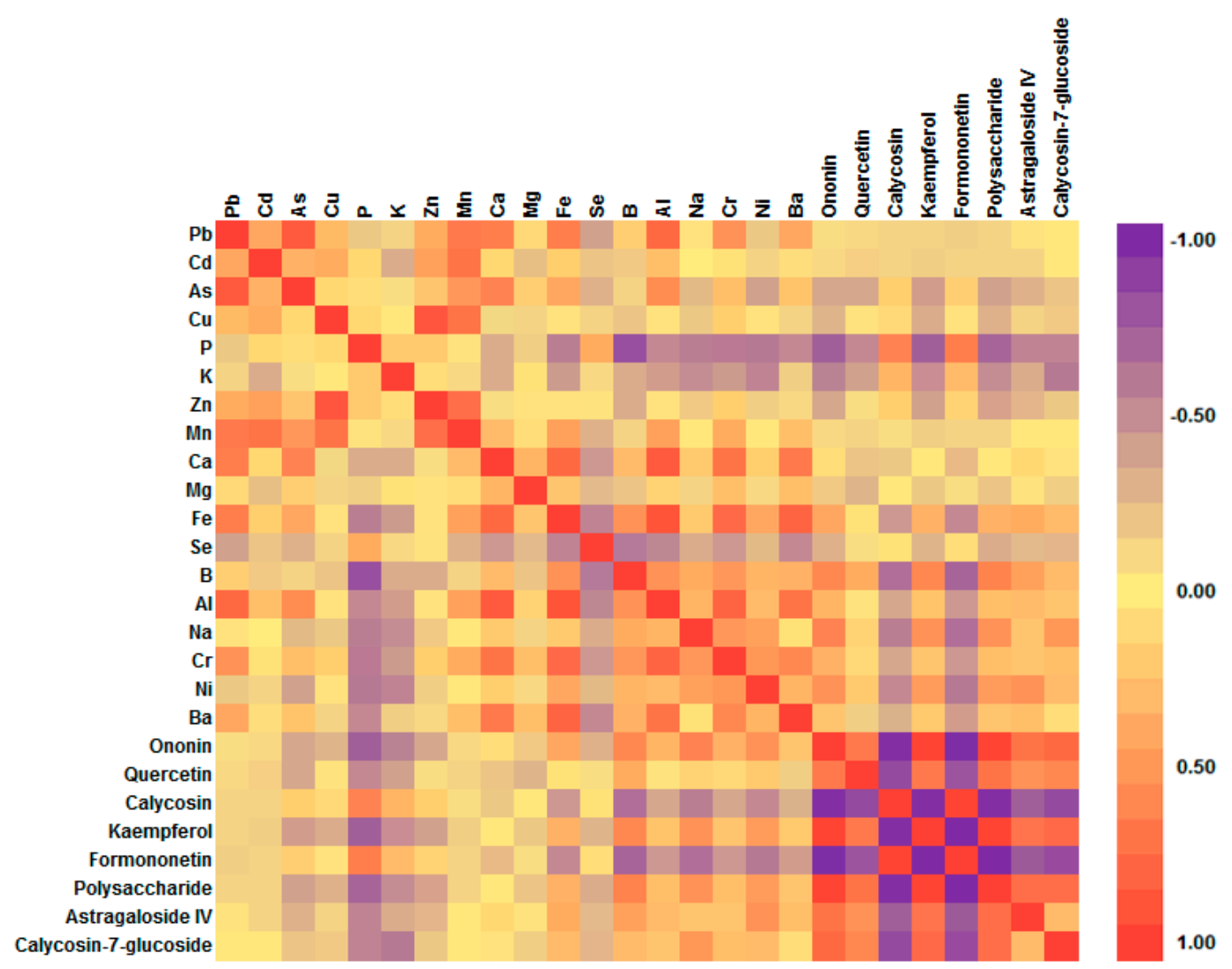

Figure 5. Correlation analysis between the contents of inorganic elements and effective components of A. mongholicus. 
Enrichment factor is applied to measure the uptake and accumulation behavior of plants. Once the value is more than 1, the plant accumulates inorganic elements from soil [28]. Figure 6 shows the enrichment factor of all $A$. mongholicus samples. The results showed that $A$. mongholicus had a high ability of enrichment for $\mathrm{P}, \mathrm{K}, \mathrm{Na}$ and $\mathrm{B}$ with the enrichment factor of 5.334, 3.184, 1.412 and 1.336, respectively. Samples collected from Shanxi accumulated considerably more $\mathrm{Fe}, \mathrm{Al}, \mathrm{Na}, \mathrm{Ni}, \mathrm{Cr}$ and As than the others, whereas the $\mathrm{Cd}, \mathrm{Cu}, \mathrm{P}, \mathrm{K}$ and $\mathrm{Zn}$ in contrast is 2 4 times lower. Moreover, A. mongholicus from Gansu had a moderate enrichment capacity. Plants from different geographical origins exhibited their own accumulation behavior, which is the basis for herb characterization by elemental pattern and can be applied for daodi and non-daodi A. mongholicus identification.

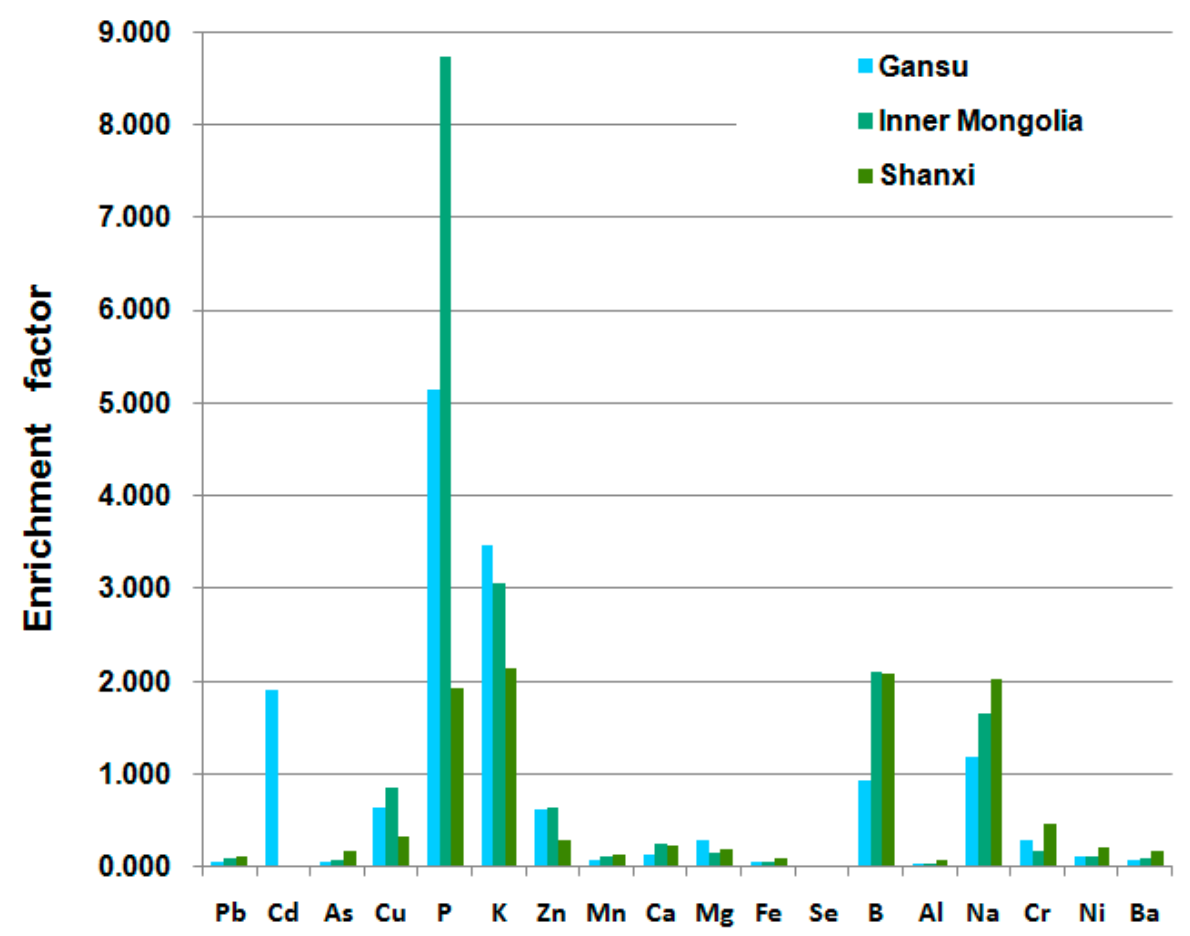

Figure 6. The enrichment factors of inorganic elements in A. mongholicus.

\subsection{Correlation Analysis}

Our previous study has shown the correlation between ecotype and quality of A. mongholicus [22-24]. The inter-relationships between selected elements and components in A. mongholicus were explored by correlation analysis. Figure 5 showed that $\mathrm{P}, \mathrm{K}$ and $\mathrm{Zn}$ had similar significant negative correlations with most of the chemical compositions. As the daodi region, plant samples from Shanxi were poor in $\mathrm{P}, \mathrm{K}$ and $\mathrm{Zn}$. Further more, the majority of the inorganic elements except $\mathrm{P}$ were negatively correlated with calycosin and formononetin. The other inorganic elements and chemical compositions also had inhibition or synergy interaction with each other in different degrees. As the main effective compounds were closely related to the pharmacodynamics activities, the contents of selected elements could reflect that the quality of $A$. Mongholicus from Shanxi were superior to others to a certain degree.

\section{Materials and Methods}

\subsection{Reagents and Apparatus}

The experimental water was ultra pure water prepared by Milli-Q (18.2 M, , Millipore, Bedford, MA, USA) water system. Concentrated $\mathrm{HNO}_{3}$ and $\mathrm{HCl}$ used for digestion were of analytical grade and were obtained from Beijing Chemical Works. All glassware was cleaned with nitric acid prior to use. Mixed standard solution was prepared by diluting $1000 \mathrm{mg} / \mathrm{L}$ standard solution of every different 
elements. A graphite furnace (EHD36-LABTECH, LabTech, Beijing, China) was employed to digest the samples. The analytes were determined by ICP-AES (ICAP6300, Thermo Scientific, West Palm Beach, FL, USA) in a simultaneous mode. Working parameters of ICP-AES are shown in Table 2.

Table 2. The operating parameters of instrument.

\begin{tabular}{cc}
\hline Parameters & Value \\
\hline Output power & $1.2 \mathrm{kw}$ \\
Auxiliary air flow & $0.2 \mathrm{~L} / \mathrm{min}$ \\
Atomization gas flow & $0.8 \mathrm{~L} / \mathrm{min}$ \\
Cooling flow & $16 \mathrm{~L} / \mathrm{min}$ \\
The observing pattern & Bidirection \\
The flux of the elevation solution & $1.5 \mathrm{~mL} / \mathrm{min}$ \\
RF-Generator & $40 \mathrm{MHz}$ \\
Replicates for each analysis run & 3 \\
Sample uptake delay & $30 \mathrm{~s}$ \\
Viewing mode & Axial \\
Spray chamber type & Cyclonic \\
Sample propulsion & Peristaltic pump, three channel \\
Torch type & Fassel type \\
Detector & Segmented-array charge-coupled (SCD)
\end{tabular}

\subsection{Sample Preparation}

Materials were collected in October 2012, including herbs and soil. The soil was scraped from the roots of herbs. The herbs were identified as Astragalus membranaceus (Fisch.) Bge var. mongholicus (Bge.) Hsiao by Professor Lin-Fang Huang associated with a researcher who came from the Key Laboratory of Bioactive Substances and Resources Utilization of Chinese Herbal Medicine, Ministry of Education, Institute of Medicinal Plant Development, Chinese Academy of Medical Sciences \& Peking Union Medical College. All herbs were washed thoroughly with tap water followed by distilled water, dried at $105^{\circ} \mathrm{C}$, grounded with a mortar and stored in the plastic bags. The soil samples were dried at $105^{\circ} \mathrm{C}$, grounded with a mortar and stored in the plastic bags.

About $1 \mathrm{~g}$ of the herbal samples was accurately weighed into a quartz digestion vessel. One milliliter of concentrated $\mathrm{HNO} 3$ and $3 \mathrm{~mL}$ of concentrated $\mathrm{HCl}$ were added to the vessel. The mixture was placed on a graphite furnace for about $12 \mathrm{~h}$ at $60^{\circ} \mathrm{C}$ before the sample was digested. After complete digestion and removal of acid for $2 \mathrm{~h}$ at $120^{\circ} \mathrm{C}$, the samples were transferred into a volumetric flask and made up to $25 \mathrm{~mL}$ with ultrapure water. The solution was taken over through the $0.22 \mu \mathrm{m}$ membrane filter and then determined by ICP-AES. The soil samples were processed in the same way.

\subsection{Calibration Procedure}

A multi element standard (1000 mg/L) was used for the preparation of standard solutions in $2 \% \mathrm{HNO}_{3}$ as well as in matrix-matched solutions for the digest solutions. The multi element stock solution was diluted to the following ten standard concentrations (mg/L): 0.05, 0.10, 0.20, 0.50, 1.0, 2.0, $5.0,10,15$, and 20. Blank solutions were prepared in the same way. Calibration ranges were modified according to the expected concentration ranges of the elements.

\subsection{Spiking Procedures}

Spiking of A. mongholicus samples and soil samples were carried out by addition of aqueous multi element standard solutions to a set of samples prepared as described above. All spiked samples were prepared in triplicate and measured by ICP-AES. 


\section{Conclusions}

In the present study, an inductively coupled plasma atomic emission spectrometry method was firstly developed for investigating inorganic element characteristics of $A$. mongholicus and its planting soil from different regions. With this approach, 21 inorganic elements were identified. Data in this work evidenced that the inorganic element characteristics as well as the uptake and accumulation behavior were significantly different among A. Mongholicus from different producing areas. The high contents of $\mathrm{Fe}, \mathrm{B}, \mathrm{Al}, \mathrm{Na}, \mathrm{Cr}$ and $\mathrm{Ni}$ could be used as indicators in the elements fingerprint to identify daodi and non-daodi A. Mongholicus. Moreover, as the main effective compounds were closely related to the pharmacodynamics activities, the contents of selected elements may reflect that the quality of A. Mongholicus from Shanxi is superior to others to some extent. This finding was in good agreement with our previous conclusions that the contents of effective components in A. mongholicus from Shanxi were more than those from Inner Mongolia and Gansu. The research provided scientific data for further study of the relationship between the content of elements and its medical therapy, and furthermore, offered references for the quality evaluation and geo-herbalism assessment of $A$. mongholicus from the perspective of inorganic elements, which will facilitate its clinical application.

Acknowledgments: Funding from the National Natural Science Foundation of China (No. 81274013, No. 81130069 and 81473315 ) is gratefully acknowledged.

Author Contributions: Linfang Huang and Lin Li designed research; Lin Li, Sihao Zheng, and Qingzhen Yang performed research; Lin Li analyzed the data and wrote the paper; and Linfang Huang and Shilin Chen revised the manuscript. All authors read and approved the final manuscript.

Conflicts of Interest: The authors declare no conflict of interest.

\section{References}

1. Zhao, Z.; Guo, P.; Brand, E. The formation of daodi medicinal materials. J. Ethnopharmacol. 2012, 140, $476-481$. [CrossRef] [PubMed]

2. Chinese Pharmacopoeia Commission. Pharmacopoeia of the People's Republic of China, 8th ed.; Chemical Industry Press: Beijing, China, 2010; pp. 283-284. (In Chinese)

3. Hong, M.J.; Ko, E.B.; Park, S.K.; Chang, M.S. Inhibitory effect of Astragalus membranaceus root on matrix metalloproteinase-1 collagenase expression and procollagen destruction in ultraviolet B-irradiated human dermal fibroblasts by suppressing nuclear factor kappa-B activity. J. Pharm. Pharmacol. 2013, 65, 142-148. [CrossRef] [PubMed]

4. Ma, C.H.; Wang, R.R.; Tian, R.R. Calycosin 7-O- $\beta$-D-glucopyranoside, an anti-HIV agent from the roots of Astragalus membranaceus var. mongholicus. Chem. Nat. Compd. 2009, 45, 282-285. [CrossRef]

5. Hepler, P.K. Calcium: A central regulator of plant growth and development. Plant Cell 2005, 17, $2142-2155$. [CrossRef] [PubMed]

6. Khanif, Y.M.; Saleem, M. Role of zinc in plant nutrition-A review. Am. J. Exp. Agric. 2013, 3, 374-391.

7. Olaiya, C.O.; Oyewole, O.E. The importance of mineral elements for humans, domestic animals and plants: A review. Afr. J. Food Sci. 2010, 4, 200-222.

8. Zheng, Q.; Shen, Q.; Guo, S. The critical role of potassium in plant stress response. Int. J. Mol. Sci. 2013, 14, 7370-7390.

9. Abou-Arab, A.A.K.; Donia, M.A.A. Heavy metals in Egyptian spices and medicinal plants and the effect of processing on their levels. J. Agric. Food Chem. 2000, 48, 2300-2304. [CrossRef] [PubMed]

10. Liu, D.H.; Guo, L.P.; Huang, L.Q.; Jin, H. Effects of mineral nutrition on metabolism of flavonoids in medicinal plants. Chin. J. Chin. Mater. Med. 2010, 35, 2367-2371.

11. Zeng, Y.; Guo, L.P.; Yang, G.; Chen, B.D.; Wang, J.Y.; Huang, L.Q. Effect of environmental ecological factors on Saponins of medicinal plant. Chin. J. Exp. Tradit. Med. Form. 2012, 17, 314-318.

12. Zhang, L.; Ye, Z.; Guo, Q. Effects of soil factor on active components of Radix Ophiopogonis. Chin. Mater. Med. 2010, 35, 1372-1377. 
13. Chen, Y.H.; Yu, M.M.; Zhu, Z.B. Optimisation of Potassium Chloride Nutrition for Proper Growth, Physiological Development and Bioactive Component Production in Prunella vulgaris L. PLoS ONE 2013, 8 , e66259. [CrossRef] [PubMed]

14. Yan, X.F.; Wu, S.G.; Wang, Y. Soil nutrient factors related to salidroside production of Rhodiola sachalinensis distributed in Chang Bai Mountain. Environ. Exp. Bot. 2004, 52, 267-276. [CrossRef]

15. Khajeh, M.; Moghaddam, A.R.A.; Sanchooli, E. Application of Doehlert Design in the Optimization of Microwave-Assisted Extraction for Determination of Zinc and Copper in Cereal Samples Using FAAS. Food Anal. Methods 2010, 3, 133-137. [CrossRef]

16. Tolalioglu, S. Determination of trace elements in commonly consumed medicinal herbs by ICP-MS and multivariate analysis. Food Chem. 2012, 134, 2504-2508. [CrossRef] [PubMed]

17. Dos Santos Walter, N.L.; Dannuza, D.C.; Samuel, M.M. Slurry Sampling and HG AFS for the Determination of Total Arsenic in Rice Samples. Food Anal. Methods 2013, 6, 1128-1132. [CrossRef]

18. Cindric, I.J.; Krizman, I.; Zeiner, M.; Kampic, S.; Medunic, G. ICP-AES determination of minor- and major elements in apples after microwave assisted digestion. Food Chem. 2012, 135, 2675-2680. [CrossRef] [PubMed]

19. Tu, Q.; Wang, T.B.; Antonucci, V. High-efficiency sample preparation with dimethylformamide for multi-element determination in pharmaceutical materials by ICP-AES. J. Pharm. Biomed. 2010, 52, 311-315. [CrossRef] [PubMed]

20. Tu, Y.G.; Zhao, Y.; Xu, M.S. Simultaneous Determination of 20 Inorganic Elements in Preserved Egg Prepared with Different Metal Ions by ICP-AES. Food Anal. Methods 2013, 6, 667-676. [CrossRef]

21. Toyama, T. Analysis of metal elements of hydrangea sepals at various growing stages by ICP-AES. Biochem. Eng. J. 2003, 14, 237-241. [CrossRef]

22. Fu, J.; Yang, S.H.; Huang, L.F. Simultaneous Determination of Six Flavonoid Active Components in Radix Astragali by UPLC. Chin. Pharm. J. 2013, 11, 916-919.

23. Yang, Q.Z.; Liu, D.W.; Wang, D.M. Correlation on quality and ecotype of Astragalus membranaceus (Fisch.) Bge. var. mongholicus (Bge.) Hsiao. Chin. Tradit. Herb. Drugs 2014, 16, 2395-2399.

24. Fu, J.; Huang, L.F.; Zhang, H.T. Structural features of a polysaccharide from Astragalus membranaceus (Fisch.) Bge. var. mongholicus (Bge.) Hsiao. J. Asian Nat. Prod. Res. 2013, 15, 687-692. [CrossRef] [PubMed]

25. WHO/FAO/IAEA. Trace Elements in Human Nutrition and Health; World Health Organization: Switzerland, Geneva, 1996.

26. Yan, L.N. Study on the Effective Components of Atractylodes Plants and Atractylodes macrocephala \& Establishment of Herbs' Element Fingerprint. Master's thesis, Hunan Normal University, Hunan, China, 30 May 2008.

27. Christine, S.A.; Mattusch, J.; Reisser, W.; Wennrich, R. Uptake and accumulation behaviour of angiosperms irrigated with solutions of different arsenic species. Chemosphere 2004, 56, 305-313.

28. Kaushik, A.; Kansal, A.; Santosh; Meena; Kumari, S.; Kaushik, C.P. Heavy metal contamination of river Yamuna, Haryana, India: Assessment by metal enrichment factor of the sediments. J. Hazard. Mater. 2009, 164, 265-270. [CrossRef] [PubMed]

Sample Availability: Not available.

(C) 2016 by the authors; licensee MDPI, Basel, Switzerland. This article is an open access article distributed under the terms and conditions of the Creative Commons Attribution (CC-BY) license (http://creativecommons.org/licenses/by/4.0/). 